\title{
EDITORIAL
}

\section{Environment, Sustainability and Equity}

Kamal Bawa *

This first issue of the second volume of Ecology, Economy and Society continues the tone set up by the first volume that focused on humanity's predicament to reconcile economic development with the need to foster environmental sustainability and achieve equity and social justice in the use of commons.

In this issue, two general commentaries question if sustainability in general and conservation of biodiversity in particular can be accomplished by the existing paradigms and approaches. The special section on ecological conflicts further highlights the inadequacy of existing institutions to address environmental justice to the detriment of both the environment and society.

Notes from the Field continue the theme of divergence between the goals of the society and institutions designed to serve people. Although most examples are from India, we know such conflicts and contradictions are pervasive everywhere. In fact, democratic traditions and institutions in India should

However, as Røpke argues in her essay the economic forces unleashed by the prevailing economic system may be too strong to move us towards a sustainable future based on environmental integrity and justice.

Interestingly, the editors did not intend the environmental justice or conflict resolution to be the themes of this issue though we admit that authors of the articles do not represent just a random sample of scholars interested in sustainability. It is clear that equity, justice and the rights of indigenous

* Coordinating Editor (2018-19). University of Massachusetts, Boston, MA 02125-3393; and Ashoka Trust for Research in Ecology and the Environment (ATREE), Bengaluru, 560 064, India; kamal.bawa@gmail.com

Copyright (C) Bawa 2019. Released under Creative Commons Attribution-NonCommercial 4.0 International licence (CC BY-NC 4.0) by the author.

Published by Indian Society for Ecological Economics (INSEE), c/o Institute of Economic Growth, University Enclave, North Campus, Delhi 110007.

ISSN: 2581-6152 (print); 2581-6101 (web).

DOI: https://doi.org/10.37773/ees.v2i1.49 
people remain dominant themes in discourses that seek to articulate and find solutions for our major environmental challenges.

Are we then making progress in addressing these challenges? Yes, but at a very slow pace. Journals such as Ecology, Economy, and Society and our "sister" journal Conservation and Society help to make progress in this direction. Certainly, what is needed is a radical transformation of the knowledge generating enterprises across the world but particularly in the global South - and at a very fast pace, because we have very little time.

First, as has been apparent for many years, we require more academic centers that will foster interdisciplinarity. Second, we must now move more rapidly towards transdisciplinarity, working with practitioners to find solutions to make an impact. Our efforts must go beyond diagnosis and understanding of the problems. It is my hope that the future issues of Ecology, Economy and Society will increasingly contain more articles on not only transformative knowledge and ideas but also how such ideas have a significant impact on resolving problems that lie at the intersection of ecology, economy, and society. 